\title{
Solid-State Bipolar Marx Generator with Voltage Droop Compensation
}

\author{
H. Canacsinh ${ }^{1,2}$, José Fernando Silva ${ }^{3,4}$, Sónia F. Pinto ${ }^{3,4}$, and Luis M. Redondo ${ }^{1,2}$ \\ ${ }^{1}$ Instituto Superior de Engenharia Lisboa, ISEL/CEEI, Lisbon, Portugal \\ ${ }^{2}$ Nuclear Physics Center from Lisbon University, CFNUL, Lisbon, Portugal \\ ${ }^{3}$ Instituto Superior Técnico, TU Lisbon, 1049-001 Lisbon, Portugal, \\ ${ }^{4}$ Center for Innovation in Electrical and Energy Engineering, 1049-001 Lisbon, Portugal
}

\begin{abstract}
This paper addresses the voltage droop compensation associated with long pulses generated by solid-stated based high-voltage Marx topologies. In particular a novel design scheme for voltage droop compensation in solid-state based bipolar Marx generators, using low-cost circuitry design and control, is described. The compensation consists of adding one auxiliary PWM stage to the existing Marx stages, without changing the modularity and topology of the circuit, which controls the output voltage and a LC filter that smoothes the voltage droop in both the positive and negative output pulses. Simulation results are presented for 5 stages Marx circuit using $1 \mathrm{kV}$ per stage, with $1 \mathrm{kHz}$ repetition rate and $10 \%$ duty cycle.
\end{abstract}

Keywords: Bipolar high-voltage pulses, Solid-state switches, Voltage droop compensation, Marx converter topology, PWM control.

\section{Introduction}

The Marx generator topology is often used to produce both unipolar or bipolar highvoltage rectangular pulses into different types of industrial and research applications [1-2]. This circuit produces high-voltage pulses by switching in series a set of capacitors into a load. The capacitors are previously charged in parallel by a relatively low voltage $d c$ power supply. The Marx generator has gained popularity by the intense utilization of semiconductors [3-4]. The use of solid-state switches enables high flexibility for changing the pulse parameters, low losses and high operation frequency, at the same time it allows for different load conditions.

However, the capacitor type discharge into the load is limited by the ratio of the energy stored in the main capacitors and the energy delivered during the pulse into the load, which depends directly on the pulse duration. If the energy delivered to the pulse is in the order of the energy stored in the main capacitors the pulse shape has no longer a rectangular shape and the capacitor voltage decay, or droop, is increasingly evident. In fact, applications that use long pulses may have a significant voltage droop by the end of the pulse. Circumventing this problem is possible by increasing the stored energy if larger capacitance is used, but this technique increases the size and cost of the circuit. 
Another approach is to build an auxiliary voltage compensation circuit. Several authors have come up with different solutions in unipolar Marx type circuits [5-8], using auxiliary resonant circuits that are charged during the charging mode of the main capacitors and deliver further energy during the pulse period when the voltage droop sets. These circuits can either be connected as an independent stage or associated in each Marx stage. However, this issue has not yet been studied in bipolar type generators, where sequences of positive and negative pulses are generated neither a PWM closed loop solution was presented.

This paper presents the first results of a novel design scheme for voltage droop compensation in solid-state based bipolar Marx generators, adding one independent auxiliary modulator stage to the existing Marx stages that performs closed loop PWM generation, without changing the modularity and topology of the circuit. The closed loop PWM generation controls the output voltage and a LC filter smoothes the voltage droop in both the positive and negative output pulses. Simulation results are presented for 5 stages Marx circuit using $1 \mathrm{kV}$ per stage, with $1 \mathrm{kHz}$ repetition rate and $10 \%$ duty cycle, into a resistive load.

\section{Contribution to Value Creation}

A closed loop PWM technique is used to generate a voltage that is superimposed to the pulse voltage generated from a solid-state Marx bipolar topology in order to compensate the voltage droop of the signal during long pulse applications. An output LC filter is added at the load stage in order to smooth the voltage. This auxiliary circuit is assembled in an extra Marx stage, without compromising the operation of the other Marx stages and satisfying the same properties in terms of maximum voltage hold-off by the semiconductors.

This novel droop voltage compensation method operates during both positive and negative pulses in a bipolar topology and will contribute to value creation by reducing costs of bipolar pulse high voltage generators which in turn can be used for example in food and sterilization industry, as well in research, enhancing economic activity and creating jobs.

\section{Circuit Topology}

Fig. 1 shows the conceptual block diagram of the bipolar solid-state Marx modulator with voltage droop compensation. The first block is the trigger system of the Marx modulator which accepts as entries the type of pulse, unipolar or bipolar pulse repetition rate and duty cycle of the pulse. It also has the voltage mode hysteresis controller that compares the output voltage and the input reference voltage to generate the switching function for the voltage droop compensation module. The second block is the Marx modulator shown in Fig. 2, comprising the voltage droop compensation module. The last two blocks are the output filter to smooth the output voltage and the resistive load. 


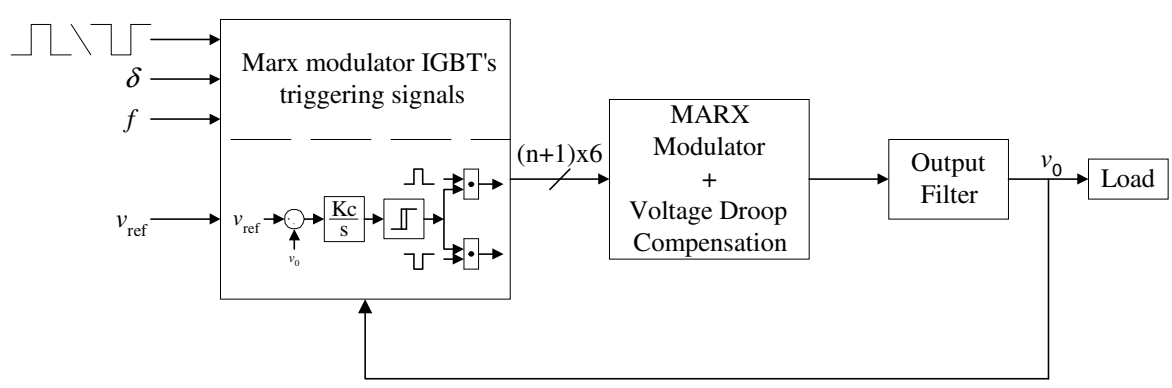

Fig. 1. Conceptual block diagram of the bipolar solid-state Marx modulator with voltage droop compensation

The simplified circuit topology which delivers either repetitive unipolar or bipolar high-voltage output pulses into a load, including the voltage droop compensation and an output filter, is presented in Fig. 2. This circuit comprises the source module, which includes the power supply $U_{d c}$ and switches $\mathrm{T}_{\mathrm{dc}}$ and $\mathrm{D}_{\mathrm{dc}}$ for charging and to avoid source $U_{d c}$ taking part in the pulse process and resistance $r_{d c}$, which represents the equivalent resistance of source module branch.

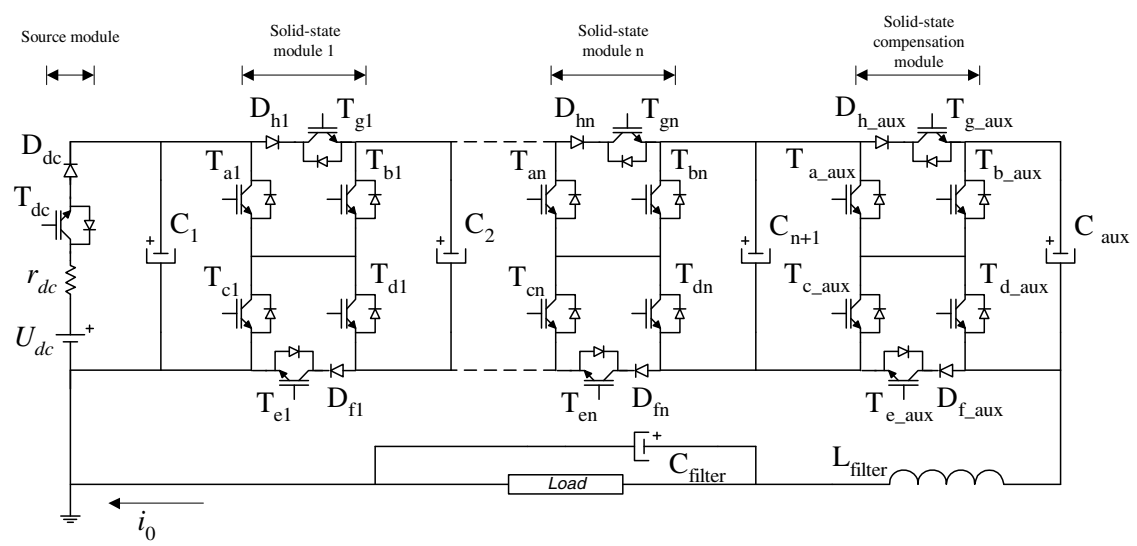

Fig. 2. General HV topology of the $\mathrm{n}$ stages solid-state Marx modulator, for unipolar or bipolar generation

All circuit stages are equal, consisting of 6 IGTBs (with anti-parallel diodes) $\mathrm{T}_{\mathrm{ai}}$, $T_{\text {bi }}, T_{c i}, T_{d i}, T_{\text {ei }}$ and $T_{\text {gi }}$, and diodes $D_{\text {fi }}$ and $D_{\text {hi }}$, where the subscript $\mathrm{i} \in\{1,2, \ldots, n$, $n+1$, aux $\}$, and two energy storing capacitors $\mathrm{C}_{\mathrm{i}}$. Thus, for $n$ semiconductor stages the circuit has $(n+1)$ capacitors, meaning that each stage needs two capacitors for producing negative and/or positive pulses, one of the capacitors being shared between two stages. The auxiliary module differs only in the triggering control system. This module includes capacitor $C_{a u x}$ for negative pulsing and $C_{n+1}$ for positive, the last being shared with $n+1$ stage. 
Fig. 2 shows an auxiliary module, the solid-state switch voltage droop compensation module. In order to not compromise the modularity concept of the Marx modulator, this module differs only from the triggering control system, consisting in IGBTs (with antiparallel diodes) $\mathrm{T}_{\mathrm{a} \_a u x}, \mathrm{~T}_{\mathrm{b} \_a u x}, \mathrm{~T}_{\mathrm{c} \_a u x}, \mathrm{~T}_{\mathrm{d} \_a u x}, \mathrm{~T}_{\mathrm{e} \_a u x}$ and $\mathrm{T}_{\mathrm{g} \_a u x}$, and diodes $\mathrm{D}_{\mathrm{f} \_a u x}$ and $\mathrm{D}_{\mathrm{h} \_a u x}$, and one energy storing capacitor $\mathrm{C}_{\mathrm{aux}}$.

\subsection{Circuit Operation}

Fig. 2 circuit presents several operating modes depending on the semiconductor switching sequence and the required output into the load (i.e. unipolar or bipolar).

Consider first the charging of capacitors $C_{i}$, from the dc charging power supply, $U_{d c}$. It consist in turning on switches $\mathrm{T}_{\mathrm{dc}}, \mathrm{D}_{\mathrm{dc}}, \mathrm{D}_{\mathrm{hi}}, \mathrm{T}_{\mathrm{gi}}, \mathrm{D}_{\mathrm{fi}}$ as shown in Fig. 3.

For semiconductor and power supply protection, during the initial charging transient, the power supply voltage amplitude is slowly raised or its output current limited to a safe value.

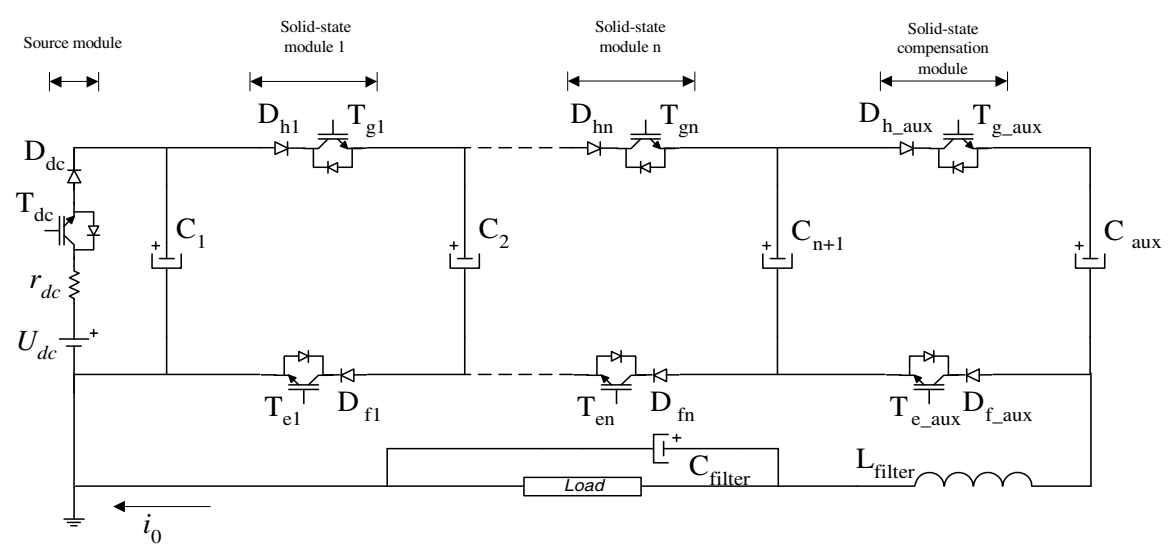

Fig. 3. Charging mode operation of the general HV topology of the n stages solid-state Marx modulator, for unipolar or bipolar generation

The on-state of $\mathrm{T}_{\mathrm{ei}}$ and $\mathrm{D}_{\mathrm{fi}}$ switches during the capacitors $\mathrm{C}_{\mathrm{i}}$ charging period guarantees that voltage $v_{0}$ applied to the load is nearly constant, being negligible in comparison to the pulse output voltage.

For negative pulse mode, switches $\mathrm{T}_{\mathrm{bi}}$ and $\mathrm{T}_{\mathrm{ci}}$ are on (except $\mathrm{T}_{\mathrm{b} \_ \text {aux }}$ and $\mathrm{T}_{\mathrm{c} \_ \text {aux }}$ ), all the remaining being off, as shown in Fig. 4. When droop compensation is functioning, the auxiliary stage is short circuited through $\mathrm{T}_{\mathrm{d} \_a u x}$ anti-parallel diode and $\mathrm{T}_{\mathrm{c} \_ \text {aux }}$ on. During this period, capacitors $C_{i}$ (except capacitor $C_{1}$ and $C_{\text {aux }}$ when compensation is not working), are connected in series and the voltage applied to the load is, nearly,

$$
v_{0} \approx-n U_{d c}
$$

assuming all capacitors charged to $U_{d c}$. 


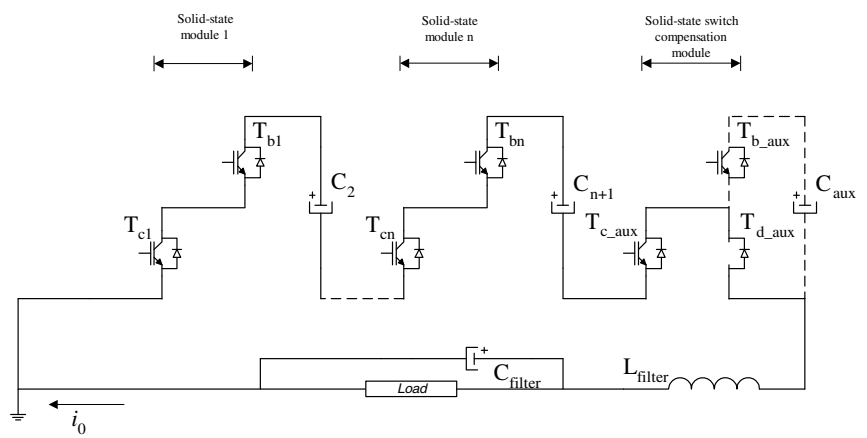

Fig. 4. Negative pulse mode operation of the general HV topology of the $\mathrm{n}$ stages solid-state Marx modulator, for unipolar or bipolar generation

For positive pulse mode, switches $\mathrm{T}_{\mathrm{ai}}$ and $\mathrm{T}_{\mathrm{di}}$ are on (except $\mathrm{T}_{\mathrm{a} \_ \text {aux }}$ and $\mathrm{T}_{\mathrm{d} \_ \text {aux }}$ ) and all the remaining are off, as shown in Fig. 5. When droop compensation is not operating, this stage is short circuited through the $\mathrm{T}_{\mathrm{c}_{-} \text {aux }}$ anti-parallel diode and $\mathrm{T}_{\mathrm{d} \text { aux }}$ on. During this period capacitors $C_{i}$ (except capacitor $C_{n+1}$ that is used in this mode for voltage droop compensation) are connected in series and the voltage applied to the load is, ideally,

$$
v_{0} \approx+n U_{d c}
$$

assuming all capacitors charged to $U_{d c}$.

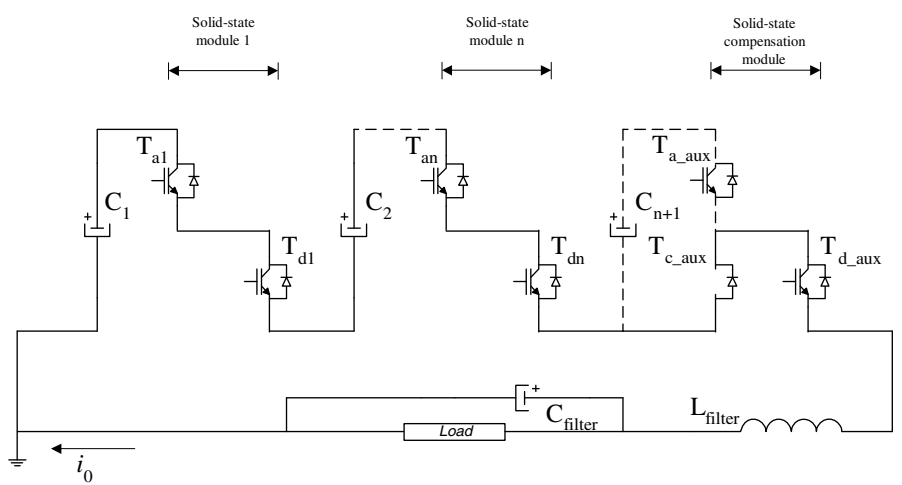

Fig. 5. Positive pulse mode operation of the general HV topology of the $n$ stages solid-state Marx modulator, for unipolar or bipolar generation

The time interval between the negative and positive pulses, called the relaxation time, can be adjusted. This time, between the negative and positive pulse, is, usually, long enough to allow re-charging the $C_{i}$ capacitors. This is useful for high load currents. Otherwise the negative and positive pulse amplitude will not be equal due to the voltage droop. 


\subsection{Voltage Droop Compensation and Filtering}

The voltage mode hysteresis controller system that generates the switching function for the voltage droop compensation module, shown in Fig. 6, integrates the difference between the output voltage and the input reference voltage with an active integrator,

$$
\frac{1}{T} \int\left(v_{r e f}-v_{0}\right) d t=0
$$

which generates a saw tooth shaped carrier that feeds a hysteretic comparator, generating the switching function to control the switches $T_{a_{\_} \text {aux }}$ or $T_{b_{\_} \text {aux }}$ of the voltage droop compensation module, with a much higher frequency than the operating Marx repetition rate.

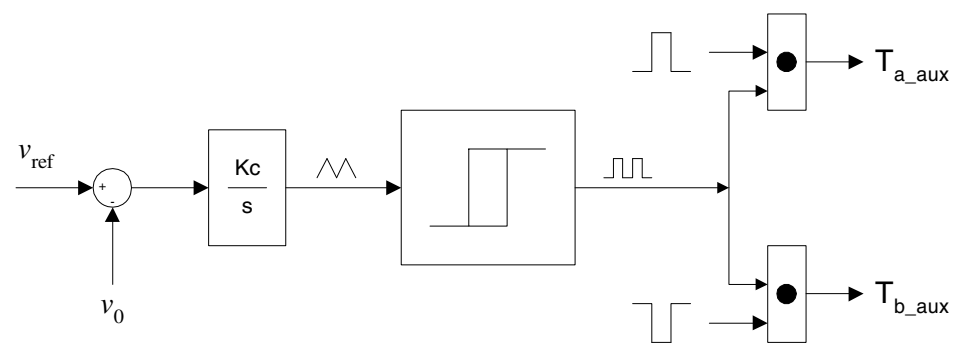

Fig. 6. Diagram of the voltage mode hysteric controller system

In negative pulse mode operation, the output voltage without compensation is generated as seen in Fig. 4. When output pulse voltage amplitude starts decreasing from its initial value, the hysteresis controller starts to reduce the error between the output voltage and the input reference voltage by modulating the switch $\mathrm{T}_{\mathrm{b}_{\text {aux }}}$ which connects the capacitor $\mathrm{C}_{\text {aux }}$ in series with the Marx modulators capacitors as can been seen in Fig. 4 (dashed line).

Positive pulse without compensation is applied into a load as seen in Fig. 5. When output pulse voltage starts decreasing, the hysteretic control module switch on $\mathrm{T}_{\mathrm{a} \_ \text {aux }}$ in order to reduce the error between the output voltage and the input reference voltage, which connects the capacitor $\mathrm{C}_{\mathrm{n}+1}$ in series with the Marx modulators capacitors as can been seen in Fig. 5 (dashed line).

Compensation results in a PWM voltage output waveform, superimposed to the normal pulse voltage shape, which needs to be smoothed. An LC filter was dimensioned, taking into account the frequency of the modulation. Once the frequency of the controller, $w$, is $100 \mathrm{kHz}$, the cut off frequency of the filter, $w_{c}$, has to be lower, so it was considered $50 \mathrm{kHz}$.

The output filter parameters, $\mathrm{L}$ and $\mathrm{C}$, was calculated based on,

$$
w_{c}=\frac{1}{\sqrt{L C}}
$$


and,

$$
\sqrt{\frac{L}{C}}=Z_{p}
$$

where $Z_{p}$ is given by

$$
Z_{p}=2 \xi R_{0}
$$

where $\xi=0,85$ and $R_{0}=1 \mathrm{k} \Omega$ is the resistive load. The LC output filter must be designed for the total output voltage.

\section{Simulation Results}

The circuit of Fig. 1, with 5 stages and voltage droop compensation stage, was simulated in SIMULINK, MATLAB software. The simulated circuit was operated with $V_{d c}=1000 \mathrm{~V}$, applying bipolar pulses with $10 \%$ duty cycle with $1 \mathrm{kHz}$ repetition rate, into a $1 \mathrm{k} \Omega$ resistive load, producing $5 \mathrm{kV} / 5 \mathrm{~A}$ pulses.

Fig. 7a) shows the simulated waveform for the bipolar output voltage into a resistive load, without any compensation, a bipolar voltage pulse, $v_{0}, 100 \mu$ s pulse width for each negative and positive pulse, and $100 \mu$ s relaxation time. It can be seen that the output voltage shape is not rectangular, showing a $500 \mathrm{~V}$ voltage droop by the end of the pulse.

Fig. 8 shows the simulated waveform for the bipolar output voltage into a resistive load, with voltage droop compensation but without any filter. It can be seen the modulation mode by Fig. 6 controller, during pulse mode operation.

Fig. 7b) shows the simulated waveform of Fig. 8a), filtered by the output LC filter, with less than $5 \mathrm{~V}$ ripple. The pulse waveform improvement is confirmed by the, almost, flat pulses obtained in comparison with Fig. 7a).

a)

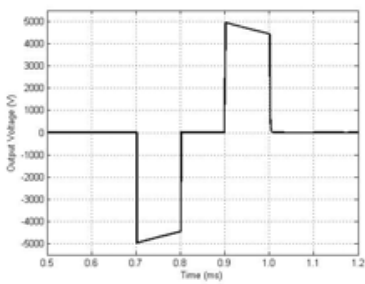

b)

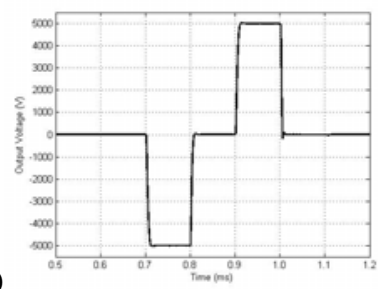

Fig. 7. Simulation output voltage result, $v_{0}$, a) without compensation; b) with compensation; vertical scale $2(\mathrm{kV} / \mathrm{div})$ and horizontal scale 0.1 (ms/div)

\section{Conclusions}

A new design scheme for voltage droop compensation in solid-state based bipolar Marx generators was proposed for high-voltage repetitive pulsed power applications. 
An independent auxiliary modulation stage was added to the existing Marx stages, without changing the modularity and topology of the circuit, which compensates the output voltage plus an output filter to smooth the voltage in both the positive and negative output pulses. As explained above the circuit keeps the voltage modularity of the Marx generator topology.

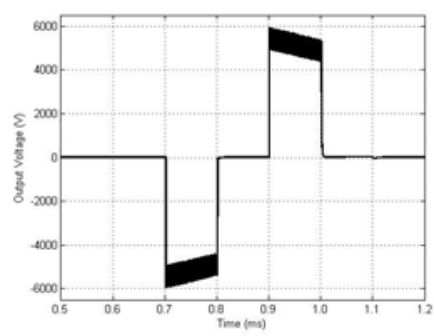

a)

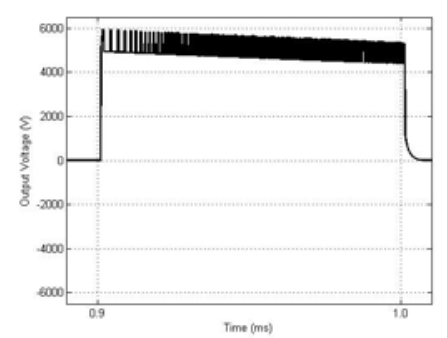

b)

Fig. 8. Simulation output voltage result, $v_{0}$, with compensation, a) bipolar pulse; b) zoom of the compensation during positive pulse; vertical scale $2(\mathrm{kV} / \mathrm{div})$ and horizontal scale 0.1 (ms/div)

Simulation results show that the voltage droop module labouring as pulse width modulation, and the output filter, compensates and smoothes the voltage droop of the pulse shape when the circuit operates with a 5 stages Marx circuit using $1 \mathrm{kV}$ per stage, with $1 \mathrm{kHz}$ repetition rate and $10 \%$ duty cycle.

\section{References}

1. Gaudreau, M.P.J., Hawkey, T., Petry, J., Kempkes, M.: Pulsed Power systems for Food and Wastewater processing. In: 23rd International Power Modulator Symposium, Rancho Mirage, CA (1998)

2. Keith, W.D., Pringle, D., Rice, P., Birke, P.V.: Distributed Magnetic Coupling Synchronizes a Staked 25-kV Mosfet Switch. IEEE Transactions on Power Electronics 15(1), 58-61 (2000)

3. Cassel, R.L.: A Solid State High Voltage Pulse Modulator which is Compact and without oil or pulse transformer. In: Power Modulator Conf., San Francisco, CA (2004)

4. Redondo, L.M., Canacsinh, H., Silva, J.F.: Generalized Solid-State Marx Modulator Topology. IEEE Transactions on Dielectrics and Electrical Insulation 16(4), 1034-1042 (2009)

5. Cassel, R.L.: Pulsed Voltage Droop Compensation for Solid State Marx Modulator. In: IEEE International Modulators and High Voltage Conference, Las Vegas, NV, USA (2008)

6. Boris, D., Biela, J., Kolar, J.W.: Optimal Design of Two-Winding Inductor Bouncer Circuit. IEEE Transactions on Plasma Science 38, 2716-2724 (2010)

7. Tang, T., Burkhart, C., Ngyen, M.: A Vernier Regulator for ILC Marx Droop Compensation. In: IEEE Pulsed Power Conference, Washington, DC, USA (2009)

8. Pfeffer, H., Bartelson, L., Bourkland, K., et al.: A Long Pulse Modulator for Reduced Size and Cost. In: 21st International Power Modulator Symposium, Costa Mesa, CA (1994) 